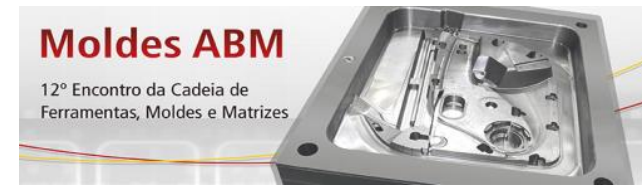

\title{
CARACTERIZAÇÃO DE AÇOS PARA MOLDES E ELABORAÇÃO DE QUADRO COMPARATIVO AÇO/PROPRIEDADE/APLICAÇÃO*
}

Caio Fernando Dias Guillen ${ }^{1}$ Cristiane Sales Gonçalves ${ }^{2}$ Paulo Haddad ${ }^{3}$

\section{Resumo}

Ao longo dos anos os aços para moldes plásticos tornam-se cada vez mais importantes no campo de aços ferramenta. A aplicação destes materiais estende-se pela indústria de processamento de diversos polímeros. Assim são esperadas propriedades específicas dos aços utilizados em cada condição: resistência mecânica, polibilidade, usinabilidade, resistência à corrosão e resposta à texturização são fatores determinantes na escolha do aço. O presente trabalho objetivou caracterizar, com relação às propriedades mais importantes para os moldes plásticos, uma gama selecionada de aços. Através de ensaios foi possível elaborar um quadro comparativo que define os aços que melhor respondem à determinada solicitação. A caracterização dos aços ocorreu através de ensaios de tenacidade, impacto, tração, dureza, características micorstruturais.

Palavras-chaves: Aços para moldes plásticos; Polímeros; Caracterização; Propriedade.

\section{CHARACTERIZATION OF PLASTIC MOULD STEEL AND ELABORATION OF COMPARATIVE TABLE WITH STEEL/PROPERTY/APPLICATION}

\section{Abstract}

During the last year the steels for plastic molds have become an important tool in the field of tool steels. Their application extends through processing industry for several polymers. Thus are expected specific properties of steels used in such processing; mechanical strength, polishability, machinability, corrosion resistance and response to texturing are determining factors in the choice of steel. The present study aimed to characterize, regarding the most important properties for plastic molds, a selected range of steels. Through testing it was possible to develop a comparative table that defines the steels that better respond to the particular request. The characterization of steels occurred through tests toughness, impact, strength, hardness, microstructural characteristics, corrosion resistance, response to texturing, polishability and machinability.

Keywords: Plastic mould tool steel; Polymers; Characterization; Property.

1 Graduando em Engenharia de Materiais, UFSCar, Estagiário Enga de Aplicação, Villares Metals S.A., Sumaré, SP, Brasil; caioguillen@hotmail.com.

2 Engenheira de Materiais, Msc. Eng. Metalúrgica e de Materiais, Engenharia de Aplicação e Assessora Técnica, Villares Metals S.A., Sumaré, SP, Brasil; cristiane.goncalves@villaresmetals.com.br.

3 Engenheiro Metalurgista, Msc. Engenharia Metalúrgica e de Materiais, Gerente Engenharia. de Aplicação e Assessora Técnica, Villares Metals S.A., Sumaré, SP, Brasil; paulo.haddad@villaresmetals.com.br. 


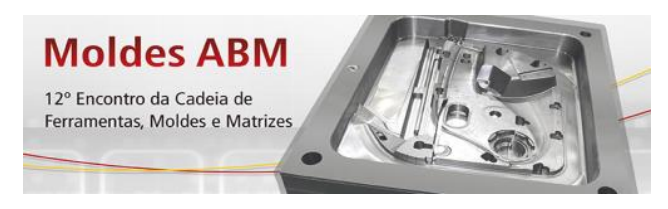

\section{INTRODUÇAO}

Durante os últimos anos os aços para moldes plásticos tornaram-se parte importante no campo de aços ferramenta. Sua aplicação estende-se pela indústria de conformação de polímeros termoplásticos, tais como trabalhos de injeção, extrusão e sopro. A Figura 1 mostra alguns exemplos destes componentes [1].

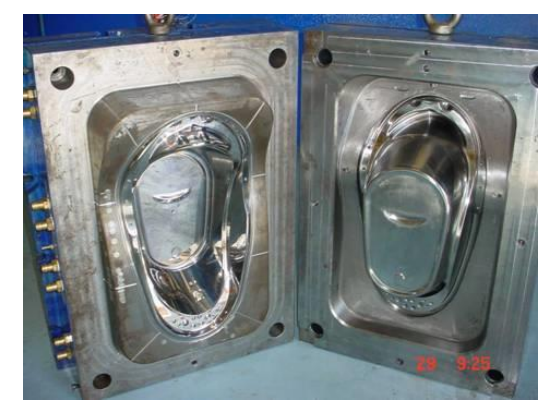

(a)

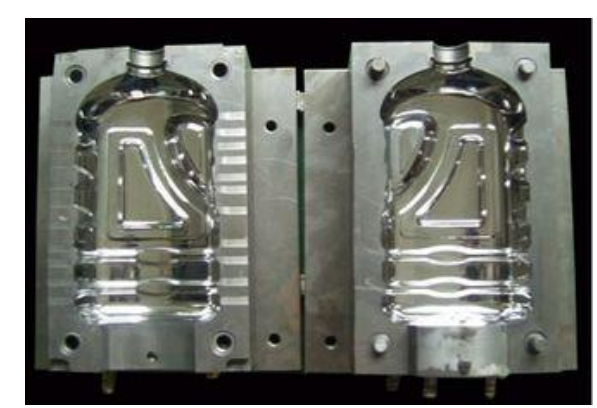

(b)

Figura 1: Aços Ferramamenta - Aplicação para moldes plásticos: (a) Molde para injeção; (b) Molde para sopro.

Esta classe é caracterizada por uma série de requisitos necessários à sua aplicação. Propriedades como resistência mecânica, resistência ao desgaste, usinabilidade, polibilidade, soldabilidade, resposta à nitretação e resposta à texturização são de extrema importância no entendimento do processo de aplicação do aço e na escolha do aço correto para determinado trabalho. Cada solicitação possui uma ou mais propriedades exigidas de maneira mais acentuada. Com isso é de extrema importância identificar a solicitação e escolher dentre os aços comercializados atualmente no mercado o mais apropriado para o processo.

Diante do exposto, este trabalho tem como objetivo classificar os aços presentes no mercado de aços para moldes plásticos, mais especificamente os aços comercializados pela Villares Metals S.A. tendo em vista suas propriedades. Com isso foi possível através de ensaios realizados nos materiais elaborar um quadro comparativo que colabora na escolha correta do aço sob uma óptica classificatória de suas propriedades.

\subsection{Revisão Bibliográfica}

\subsubsection{Resistência mecânica e ao desgaste}

O aço deve possuir resistência suficiente para a dada aplicação, evitando a ocorrência de deformação plástica sob pressão. A resistência mecânica dos aços para moldes é basicamente dada pela dureza após tratamento térmico. É também importante a relação entre a dureza e a facilidade de polimento do molde, sendo esta tanto maior quanto mais dura a superfície a ser polida. Muitos moldes possuem cavidades profundas e, nestes casos, a dureza deve ser também adequada nas regiões do núcleo do material.

Plástico líquido em alta pressão, especialmente quando contém adições de carga, pode gerar desgaste da superfície do molde. As partículas de carga ou mesmo as fibras possuem normalmente dureza muito superior ao aço utilizado que, associada à alta velocidade de deslizamento e à pressão de contato, causam desgaste tipo

* Contribuição técnica ao $12^{\circ}$ Encontro da Cadeia de Ferramentas, Moldes e Matrizes, 6 e 7 de agosto de 2014, São Paulo, SP, Brasil. 


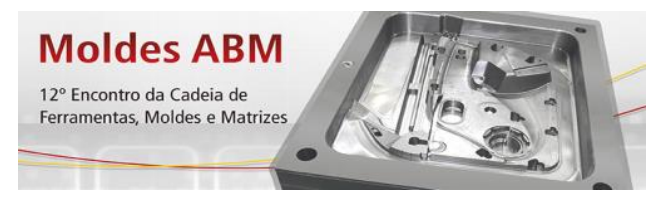

abrasivo. Deste modo, a resistência ao desgaste do aço ferramenta utilizado é importante para algumas aplicações, incluindo moldes para plásticos de engenharia. Além do aço utilizado, a resistência ao desgaste também depende de tratamentos superficiais, como por exemplo, a nitretação. Estes tratamentos, além de aumentar a resistência ao desgaste também podem melhorar as condições de polimento, pela maior dureza superficial obtida, e as condições de desmoldagem das peças, pela sua influência no coeficiente de atrito.

\subsubsection{Usinabilidade}

O elevado volume de material removido na confecção dos moldes torna a usinabilidade do aço empregado muito importante para os moldes de plástico. A usinabilidade de um material depende de fatores metalúrgicos e das condições de usinagem como ferramenta e velocidade de corte, sendo um resultado de interação do metal com a operação de usinagem. O termo é geralmente usado para expressar o estado da superfície usinada, a taxa de remoção de material, a facilidade de saída do cavaco ou a vida da ferramenta [2-3]. Do ponto de vista das características básicas do aço, a sua usinabilidade deve ser melhorada para reduzir não só o consumo de ferramentas, mas principalmente o tempo de usinagem.

A usinabilidade de um aço para moldes depende das propriedades mecânicas e físicas do aço, relacionadas à sua composição química, mas também dos processos utilizados para sua produção. Por exemplo, blocos para fabricação de moldes de grandes dimensões exigem a produção na aciaria a partir de grandes lingotes, os quais por sua vez exigem adequado refino secundário para eliminação de inclusões grosseiras. A subsequente deformação em prensa com alta potência é importante para refinar a microestrutura e eliminar defeitos do fundido.

A melhoria da usinabilidade dos aços pode ser obtida por diversas formas [4], sendo uma delas a utilização de teores residuais de enxofre ligeiramente elevados [5]. Este elemento forma inclusões com o manganês (sulfeto de manganês - MnS), as quais possuem baixo ponto de fusão e alta deformabilidade, melhorando a usinabilidade. Tais inclusões causam um efeito lubrificante nas arestas de corte e facilitam a quebra do cavaco na zona de cisalhamento. Em aços produzidos pela rota convencional, as inclusões tipo MnS tornam-se alongadas após a deformação no processo de forjamento, sendo tanto mais grosseiras quanto maior o bloco produzido. Assim, podem comprometer a polibilidade e, consequentemente, aços fabricados pela rota convencional normalmente empregam reduzidos teores de $\mathrm{S}$.

\subsubsection{Polibilidade}

A aplicação de polimento em aços para moldes plásticos está intimamente relacionada à necessidade de refletividade e apelo visual de alguns componentes da indústria como faróis, CDs, lentes, carcaças de eletrodomésticos, entre outros. Entretanto, a obtenção de reprodutibilidade dos resultados e avaliação dos desvios evidenciados ou provenientes desta etapa constitui uma fonte de questionamento para os setores envolvidos na manufatura de moldes plásticos.

O processo de polimento é muito complexo e a avaliação de sua qualidade ainda não possui um método bem estabelecido. A maioria das práticas emprega uma avaliação visual da superfície do molde. A rugosidade do molde ou outras avaliações tem se provado insuficientes em uma grande quantidade de condições; como na previsão do fenômeno "casca de laranja" ou outros defeitos localizados, nos quais o

* Contribuição técnica ao $12^{\circ}$ Encontro da Cadeia de Ferramentas, Moldes e Matrizes, 6 e 7 de agosto de 2014, São Paulo, SP, Brasil. 


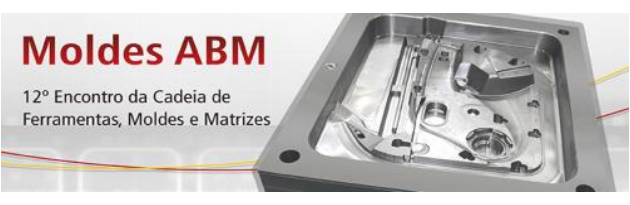

material apresenta uma rugosidade adequada, mas não uma aparência ótica apropriada para o componente plástico [4].

\subsubsection{Resistência à corrosão}

Plásticos ou compostos de moldagem de plástico são geralmente considerados como quimicamente não agressivos. Mas certas condições de operação podem fazer exigências extremas em aços de moldes de plástico em termos de resistência à corrosão. Por exemplo, quando o processamento de policloreto de vinila (PVC) com um tempo de espera prolongado acima de $165^{\circ} \mathrm{C}$, o cloreto de hidrogênio é libertado para formar ácido clorídrico em combinação com a humidade do ar. Ataque químico também pode resultar a partir de ácido etanoico sendo liberado durante o processamento de acetato de celulose. Enchimentos em compostos de moldagem de plástico, tais como aditivos retardadores de chama com base em cloro ou bromo, também têm um efeito corrosivo.

Os aços para moldes podem ser protegidos contra corrosão por galvanização, cromagem dura ou niquelamento. Mas, surgem dificuldades com impressões intrincadas, uma vez que não é possível atingir uma espessura de revestimento uniforme. Também não é possível produzir peças de plástico, em grande parte sem costura, uma vez que as linhas de separação são sempre ligeiramente arredondadas. Quando o molde é sujeito a um nível mais elevado de carga de flexão, também existe o perigo de o quebra camada de cromo e até descamação. Em muitos casos, portanto, é melhor a utilização de aços inoxidáveis martensíticos que são resistentes à corrosão.

O tratamento térmico destes aços ocorre por processo de têmpera e revenimento. Durante este processo, o tipo, quantidade e distribuição dos carbonetos precipitados, tem uma influência decisiva sobre a resistência à corrosão de aços de moldes de plástico. Precipitação fina de carbonetos (produzidos em baixa temperatura de revenimento, até $400^{\circ} \mathrm{C}$ ) serve para aliviar a martensita obtida póstêmpera. Estes aços resistentes à corrosão também podem ser revenidos na zona de máxima de dureza secundária para atingir a dureza e tenacidade adequada, porém há uma penalização significativa em termos de resistência à corrosão [6].

\subsubsection{Nitretação}

A nitretação é utilizada para enriquecer a camada superficial de moldes ou de componentes de aço com nitrogênio. Para este efeito, as peças de trabalho são expostas a um meio rico em nitrogênio ou nitrogênio e carbono, a temperaturas de $500-550^{\circ} \mathrm{C}$. Estas temperaturas relativamente baixas não causam transformações na microestrutura mesmo durante o aquecimento ou o resfriamento, havendo o mínimo de distorções ou empenamentos.

Enriquecimento de nitrogênio na zona de superfície proporciona numerosas vantagens em moldes para plástico, tais como:

- Alta dureza na superfície e boa resistência ao desgaste abrasivo;

- Reduz a aderência do molde, pois a camada nitretada funciona como uma camada cerâmica;

- Aumenta à resistência a corrosão em aços baixa liga, com boa estabilidade dimensional e polibilidade.

Nitretação a plasma e a gás são os principais processos estabelecidos na fabricação de moldes de plástico. No processo de nitretação, a zona de superfície é enriquecida

* Contribuição técnica ao $12^{\circ}$ Encontro da Cadeia de Ferramentas, Moldes e Matrizes, 6 e 7 de agosto de 2014, São Paulo, SP, Brasil. 


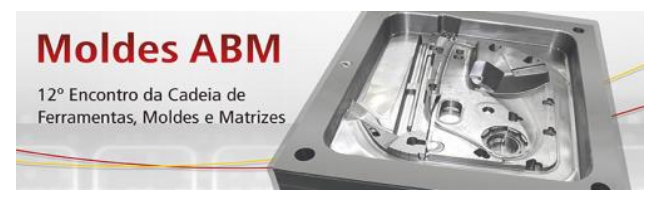

com nitrogênio. Tal como no caso de carbonetação, um gradiente de concentração de nitrogênio é estabelecido a partir da superfície para o núcleo $[7,8]$.

\subsubsection{Texturização}

Processos de texturização, também conhecidos como de granulação ou gravura, são amplamente utilizados na indústria de moldes plásticos para a produção de superfícies diferenciadas. A faixa de possibilidades de acabamentos superficiais por texturização é praticamente ilimitada. De modo geral, a textura mais popular é de imitação de couro, largamente utilizada em componentes da indústria automobilística, além da imitação de madeira para mobílias e acabamentos neutros de fácil limpeza para aplicações domésticas [9]. Ainda há a possibilidade de mistura de múltiplas texturas. A construção de um logo da companhia ou um padrão na aparência do componente que possa imediatamente identificar a peça como pertencente a uma empresa em particular também torna o processo atrativo. Além disso, há a possibilidade de inserção de números, identificações ou instruções aos consumidores na peça que eliminam a necessidade de um processo secundário como uma estampagem a quente ou a utilização de rótulos [10].

A vasta aplicação de texturas em componentes plásticos não se dá somente pelo apelo estético e econômico agregado ao produto, mas também devido a razões funcionais. A modificação superficial do componente permite alteração de seu coeficiente de atrito, tornando mais fácil o manuseio de peças plásticas [11] como, por exemplo, em bastões de esqui e cabos de ferramentais, sendo também utilizadas em aplicações de segurança como em tapetes de borracha. $\mathrm{O}$ aumento da região superficial da peça pelo processo pode, também, favorecer aplicações de fluxo de calor [10]. Além disso, componentes texturizados apresentam maior resistência ao risco e ao desgaste, e o acabamento alcançado esconde algumas irregularidade devido ao processo de injeção, como marcas de fluxo, redemoinhos e rechupes [9]. A textura aplicada em um design e localização corretos pode ainda ajudar a minimizar a existência de fluxos turbulentos no processo de injeção [10].

Devido às inúmeras possibilidades e vantagens do processo, a texturização é utilizada nas indústrias de eletrodomésticos, eletroeletrônicos, utilidades domésticas, calçados, construção civil e de embalagens, tendo como seus principais e mais exigentes clientes as montadoras, que correspondem em média a $80 \%$ do faturamento das principais prestadoras desse serviço [12]. Esse setor exige impecável uniformidade da textura das peças dos modelos mundiais de automóveis, sendo que as empresas devem ser homologadas para a produção das mesmas. Apesar da qualidade requerida pelas montadoras, essas oferecem baixo retorno às empresas de texturização, devendo todo e qualquer desvio de processo que gere perdas ser evitado. Dessa forma, a qualidade do aço e o controle de todos os parâmetros no procedimento são essenciais para obtenção de reprodutibilidade e qualidade no acabamento superficial do molde.

\footnotetext{
* Contribuição técnica ao $12^{\circ}$ Encontro da Cadeia de Ferramentas, Moldes e Matrizes, 6 e 7 de agosto de 2014, São Paulo, SP, Brasil.
} 

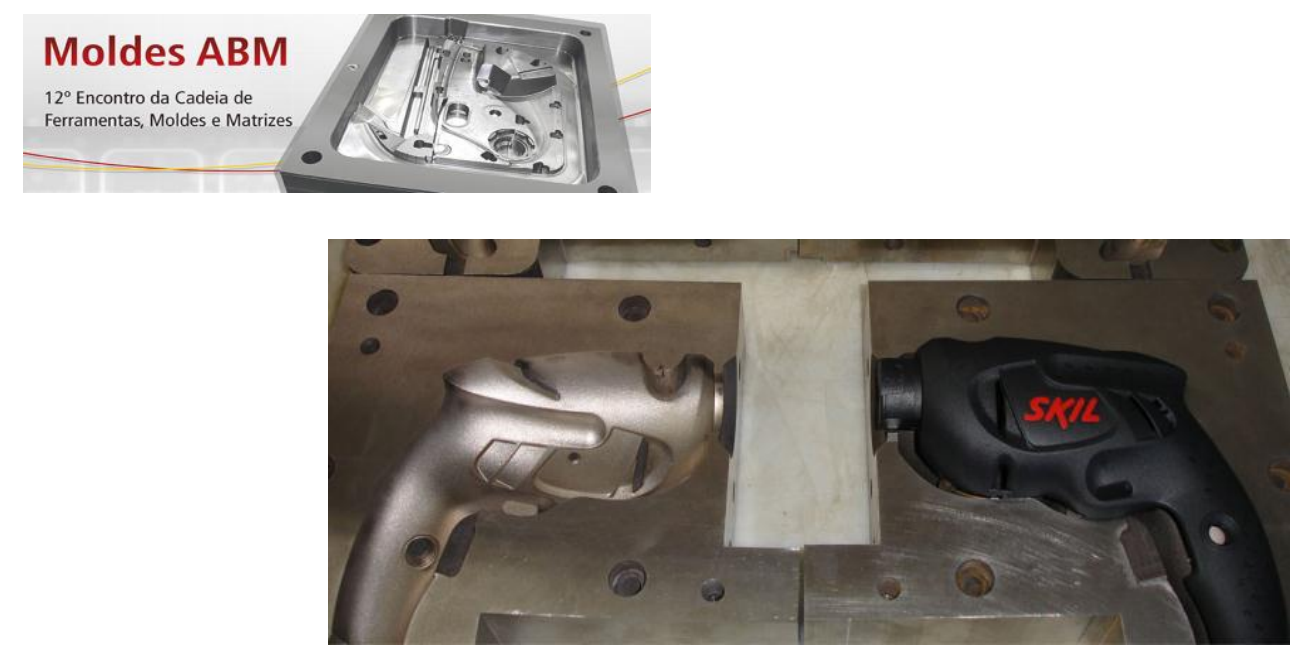

Figura 2: Molde para produção do envoltório plástico de furadeiras [5].
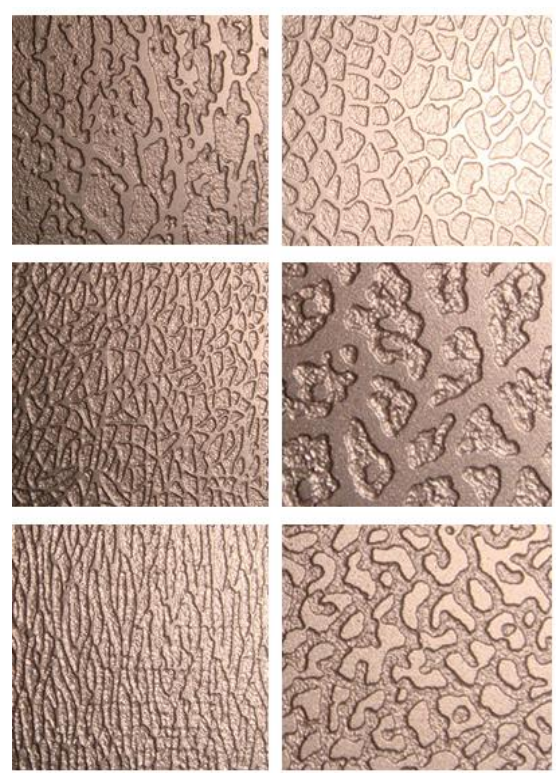

Figura 3: Exemplos da Variedade de texturas em superfícies metálicas [5].

\section{MATERIAIS E MÉTODOS}

Para desenvolver novas ligas para aplicações na indústria de transformação de plástico é necessário conhecer o atual estado da arte. Portanto, materiais referência do mercado, provenientes de uma empresa também referência, foram investigados quanto ao seu comportamento: dureza, microestrutura e resistência mecânica. Segue abaixo os aços selecionados para o estudo:

- VP20ISO ( DIN 1.2738)

- VP100 (Patente Villares Metals S.A.)

- $\operatorname{VIMCOR}(\sim$ DIN 1.4548)

- VP420T ( DIN 1.2083)
- $\quad$ VH13IM (AISI H13 Refundido)

- $\mathrm{N} 2711 \mathrm{M}$ ( DIN $1.2711 \mathrm{mod}$.)

- VP ATLAS (Patente Villares Metals S.A.)

Os aços apresentam primeiramente o nome comercial referente à marca Villares Metals S.A., que forneceu o material e a infraestrutura para o trabalho e em entre parêntese a norma que rege similarmente a composição e produção do aço. Tais aços englobam de maneira variada diversas propriedades exigidas no processamento de moldes plástico A Tabela 1 apresenta a composição química nominal para os materiais estudados.

\footnotetext{
* Contribuição técnica ao $12^{\circ}$ Encontro da Cadeia de Ferramentas, Moldes e Matrizes, 6 e 7 de agosto de 2014, São Paulo, SP, Brasil.
} 


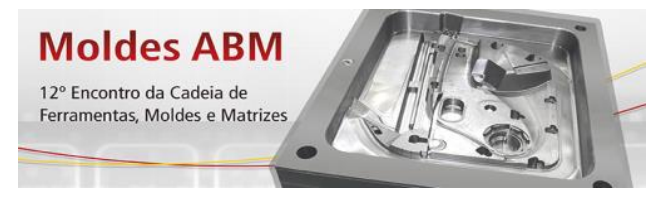

Tabela 1. Ligas e composição química (\% em peso) [13].

\begin{tabular}{|c|c|c|c|c|c|c|c|c|}
\hline Liga & Norma & C & Cr & V & Mo & Si & Mn & Ni \\
\hline VP20ISO & $\sim$ DIN 1.2738 & 0.36 & 1.85 & - & 0.20 & - & 1.60 & 0.75 \\
\hline VP100 & $\sim$ DIN 1.2738 & 0.22 & 0.58 & 0.15 & & 0.40 & 1.9 & - \\
\hline VIMCOR & $\sim$ DIN 1.4548 & 0.05 & 12.00 & - & - & 0.40 & 2.50 & - \\
\hline VP420T & $\sim$ DIN 1.2083 & 0.40 & 13.50 & 0.25 & - & 0.80 & 0.50 & - \\
\hline N2711M & $\sim$ DIN 1.2711 mod. & 0.56 & 1.10 & 0.07 & 0.48 & - & 0.70 & 1.65 \\
\hline VP ATLAS & - & 0,25 & 1,90 & 0,07 & 0,70 & 0,20 & 1,60 & 0,60 \\
\hline VH13IM & AISI H13 Refundido & 0.40 & 5.20 & 0.90 & 1.30 & 1.00 & 0.35 & - \\
\hline
\end{tabular}

Todos os aços foram submetidos a ensaios de impacto, tração, análise microestrutural, de microinclusões, dureza e verificação da composição química.

Através de análise dos resultados e informações obtidas em revisão bibliográfica foi possível estabelecer um critério de avaliação classificatório simples indicando o aço que melhor responde á uma solicitação de propriedade.

\section{RESULTADOS}

\subsection{Análise Química}

Todos os aços apresentaram composição química que correspondem com a norma que rege o material e as informações fornecidas em catálogo pela Villares Metals S.A.

\subsection{Microestutura e Microinclusões}

A Tabela 2 apresenta resumidamente as microestruturas e resultados quanto à presença de microinclusões dos materiais estudados.

Tabela 2: Fotos microestrutura e classificação de microinclusões e condição de tratamento.

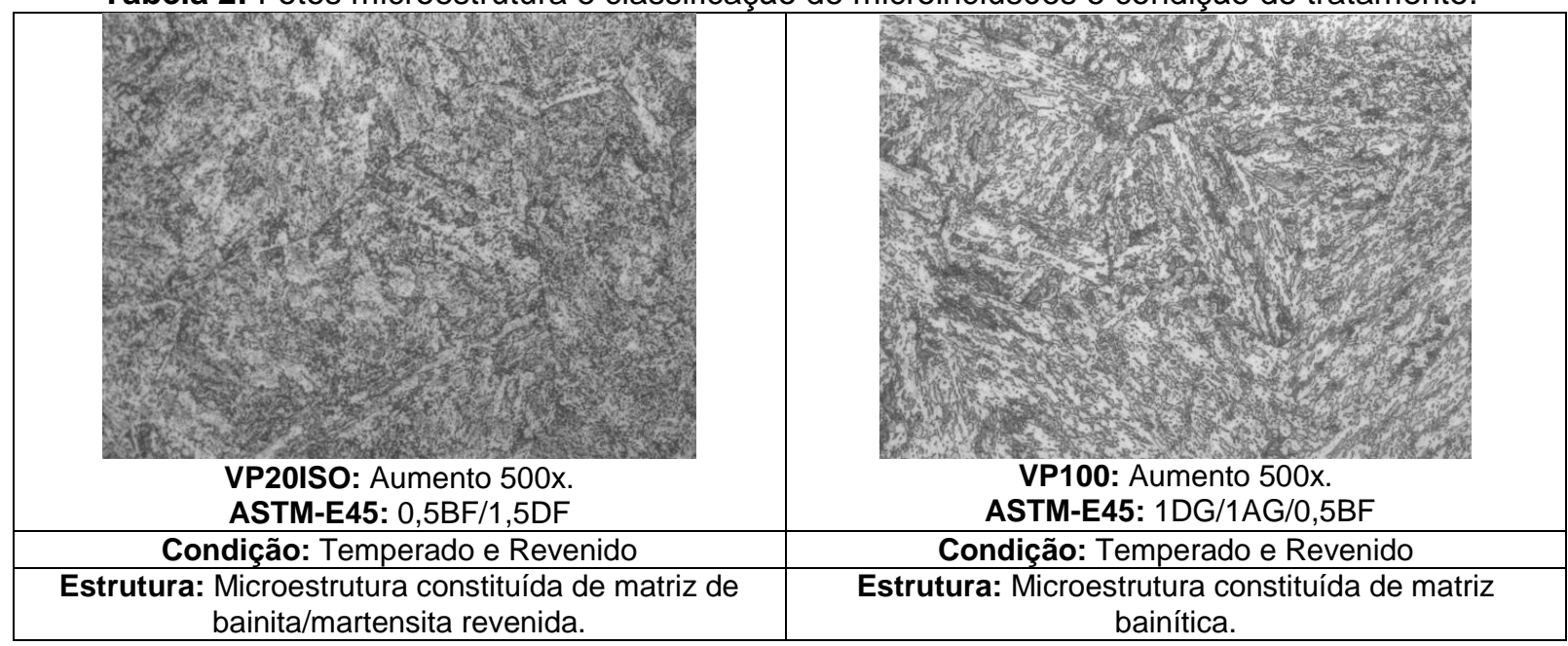

* Contribuição técnica ao $12^{\circ}$ Encontro da Cadeia de Ferramentas, Moldes e Matrizes, 6 e 7 de agosto de 2014, São Paulo, SP, Brasil. 

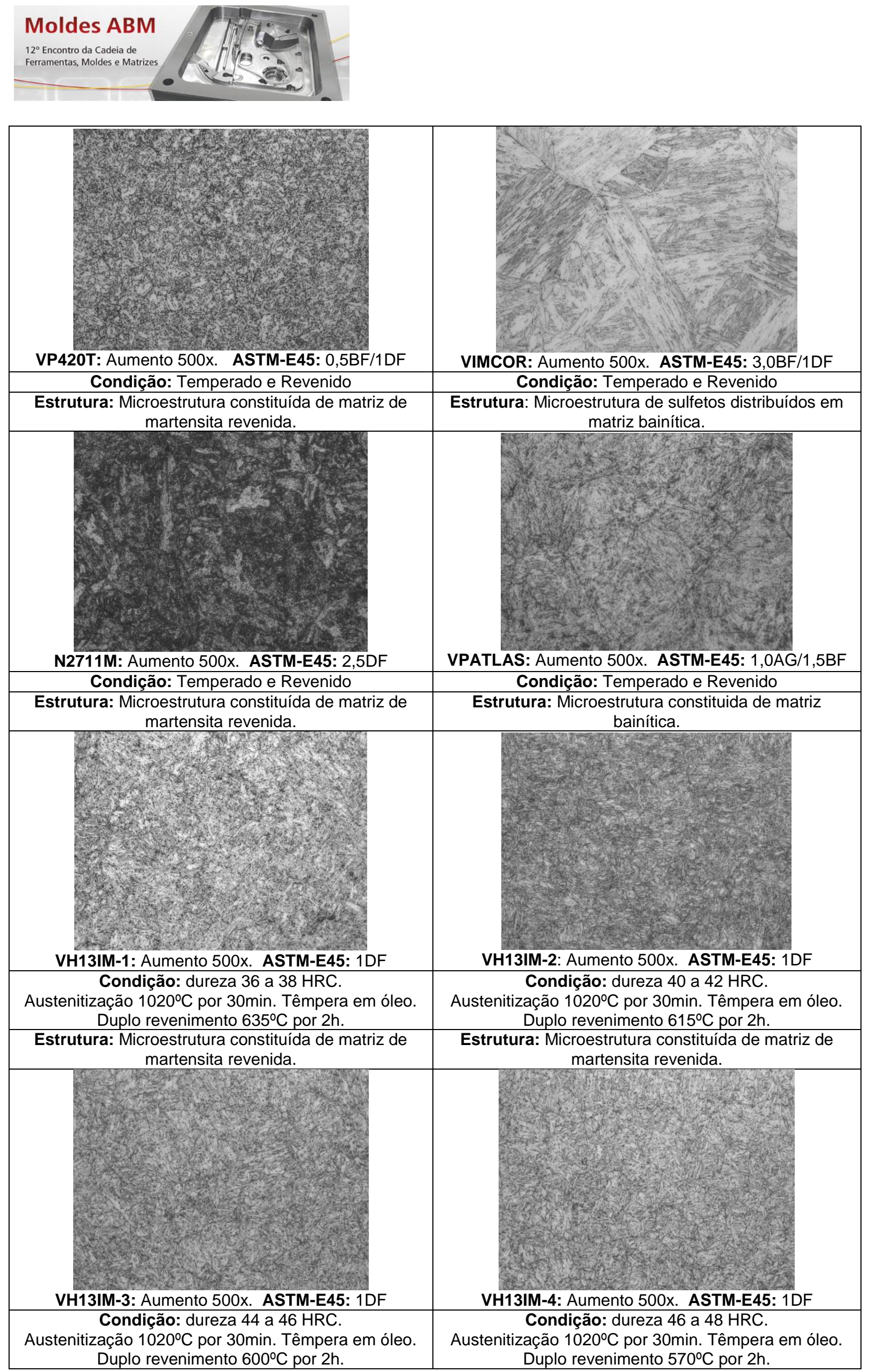

* Contribuição técnica ao $12^{\circ}$ Encontro da Cadeia de Ferramentas, Moldes e Matrizes, 6 e 7 de agosto de 2014, São Paulo, SP, Brasil. 


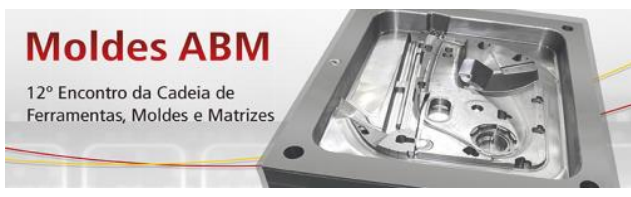

\subsection{Ensaios Mecânicos}

Tabela 3: Resumo dos resultados obtidos nos ensaios mecânicos.

\begin{tabular}{|c|c|c|c|c|}
\hline Aço & Dureza (HRC) & $\begin{array}{c}\text { Tração - LR - } \\
\text { (Mpa) }\end{array}$ & $\begin{array}{c}\text { Impacto c/ } \\
\text { entalhe (J) }\end{array}$ & $\begin{array}{c}\text { Impacto s/ } \\
\text { entalhe (J) }\end{array}$ \\
\hline VP20ISO & 30,0 & 974,3 & 19,7 & 280,9 \\
VP420T & 30,9 & 1024,9 & 3,1 & 148,4 \\
VP100 & 32,5 & 1011,8 & 5,6 & 204,7 \\
VIMCOR & 30,0 & 971,1 & 5,0 & 286,5 \\
\hline N2711M & 37,7 & 1213,8 & 16,3 & 258,3 \\
VPATLAS & 38,2 & 1270,1 & 9,8 & 258,2 \\
\hline VH13IM-1 & 36,3 & 1187,1 & 113,5 & 362,6 \\
VH13IM-2 & 42,7 & 1478,1 & 53,3 & 423,3 \\
VH13IM-3 & 44,5 & 1365,2 & 39,3 & 429,6 \\
VH13IM-4 & 48,3 & 1723 & 26,6 & 461,7 \\
\hline
\end{tabular}

A Tabela 3 apresenta resumidamente os resultados encontrados nos ensaios de dureza, tração e impacto. Através dos ensaios foi possível identificar nos materiais o seu comportamento, com isso é possível notar algumas conclusões. O aumento da dureza no material, seja ela pela composição ou condição de tratamento térmico, pode ser relacionado diretamente com o aumento da resistência mecânica, sendo assim o material com maior dureza apresenta menor desgaste na utilização. Os ensaios de impacto são relacionados com a vida útil do material submetido a ciclos de utilização, deste obtém-se o valor da tenacidade que quanto maior, mais tempo o material terá de vida útil sem sofrer falhas como trincas ou rupturas prematuras. A classificação das microinclusões nos fornece informações importantes relacionadas à polibilidade e usinabilidade dos materiais, a presença de algumas partículas nos diz se o material tem maior ou menor facilidade em ser usinado e polido.

\section{CONCLUSÃO E QUADRO DE CLASSIFICAÇÃO}

Com os resultados e o estudo exibidos acima foi possível elaborar um quadro de seleção de aços para moldes plásticos tendo em vista suas propriedades. Para melhor entendimento, o quadro foi organizado de maneira classificatória no sentido da esquerda para direita, assim, os aços que possuem a propriedade em questão em vantagem estão localizados á direita. Didaticamente houve o posicionamento do aço VP20ISO (P20) na região central, pois é o aço comercialmente mais utilizado na indústria de moldes plásticos e suas características e propriedades são bem conhecidas pelo setor, possibilitando assim comparar os demais utilizando o VP20ISO como referência.

\footnotetext{
* Contribuição técnica ao $12^{\circ}$ Encontro da Cadeia de Ferramentas, Moldes e Matrizes, 6 e 7 de agosto de 2014, São Paulo, SP, Brasil.
} 


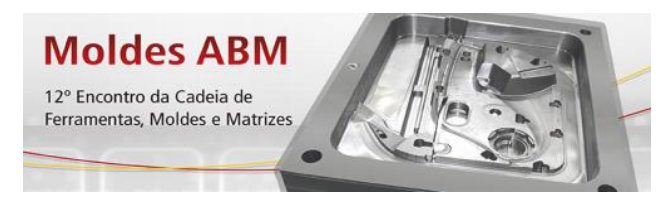

\section{Quadro de classificação}

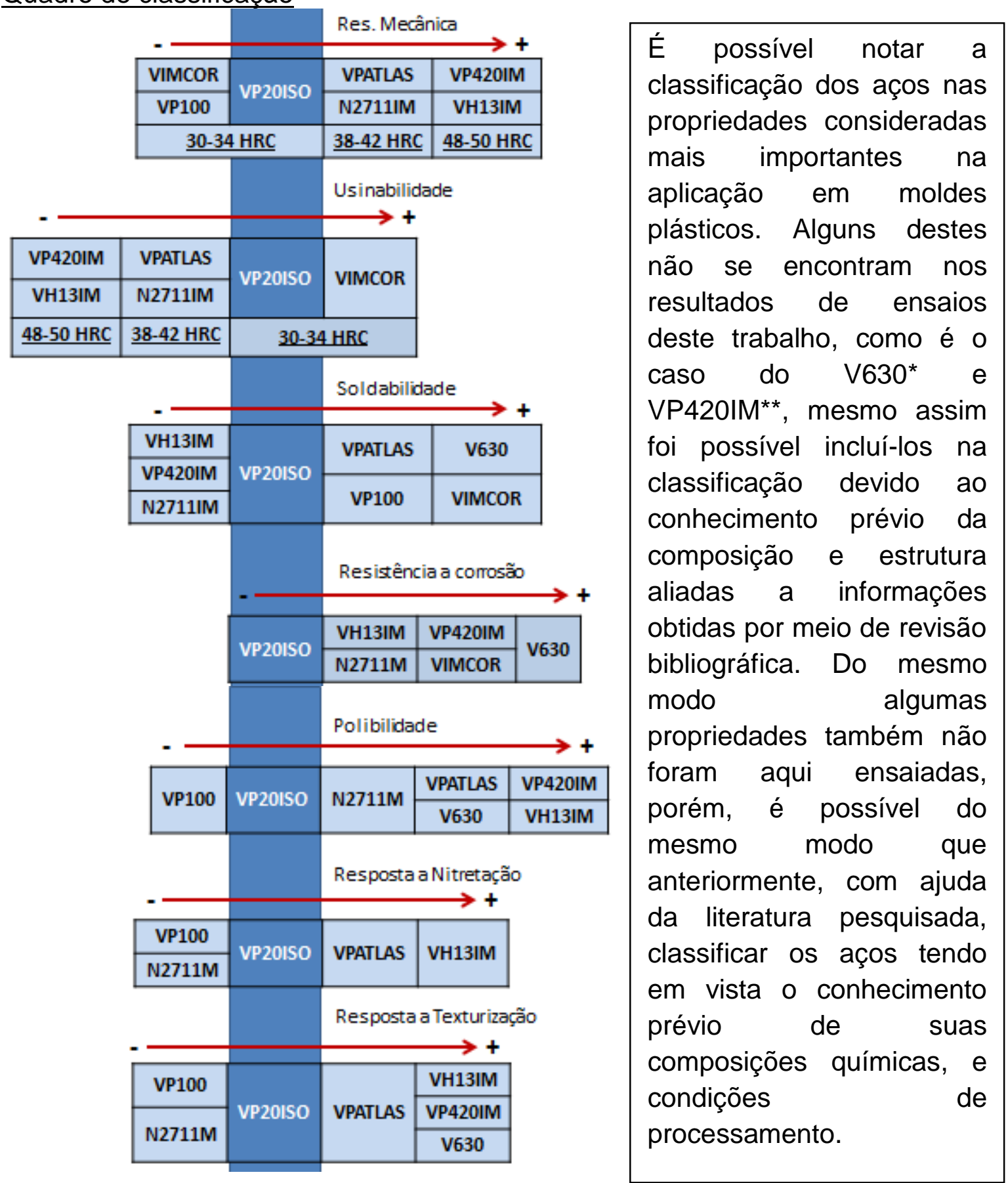

*V630 - aço inoxidável endurecido por precipitação do tipo 17-4 PH. É uma liga a base de CrNiCuNb e baixo teor de $C$. Este balanceamento químico favorece melhor soldabilidade, polibilidade e resistência a corrosão. $O$ tratamento térmico de envelhecimento permite que o material seja aplicado em diversas faixas de resistência mecânica.

**VP420IM - aço inoxidável martensitico, produzido por refusão ESR. Por se tratar de material refundido, o mesmo apresenta quantidade de microinclusões em níveis extremamente baixos, favorecendo maior polibilidade. Por se tratar de material que contem aproximadamente $0,4 \% \mathrm{C}$, ao ser temperado e revenido, pode atingir dureza de até 52 HRC.

Figura 4: Quadro de classificação dos aços para moldes plásticos de acordo com a propriedade.

\footnotetext{
* Contribuição técnica ao $12^{\circ}$ Encontro da Cadeia de Ferramentas, Moldes e Matrizes, 6 e 7 de agosto de 2014, São Paulo, SP, Brasil.
} 


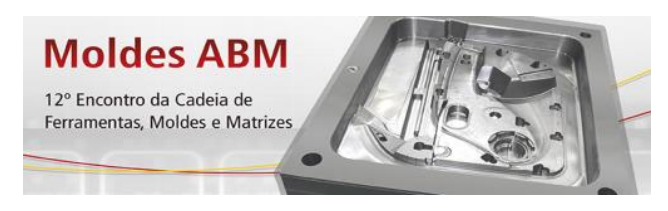

\section{REFERÊNCIAS}

1 Lichtenegger G., Schneider R., Sammer J., Schirninger G., Wurzinger P., Neuherz J. Development of a nitrogen alloyed tool steel. In: Proc. 5th International Conference on Tooling; 1999; University of Leoben, Austria. p.643.

2 Tipnis V., Joseph R. Influence of Metallurgy on Machinability - Testing for Machinability. ASM; 1975. p.11.

3 Cook N. Influence of Metallurgy on Machinability - What is Machinability. ASM; 1975. p.1.

4 Mesquita RA, Sokolowski A, Barbosa CA. Desenvolvimento de aços especiais com usinabilidade melhorada. Revista Máquinas e Metais. 2003;mai.:86-112.

5 Polimaster Moldes. [acessado em 27 nov. 2012]. Disponível em: www.polimastermoldes.com.br.

6 Skoog DA, Holler FJ, Nieman TA. Princípios de análise instrumental. 5ª ed. Bookman; 1998.

7 Eckstein HJ. Technologie der Warmebehandlung von Stahl. Leipzig: VEB Destscher Verlag fur Grundstoffindustrie; 1977.

8 Liedtke D, Jonsson R. Warmebehandlung, expert verlag. Renningen; 1996.

9 Hippenstiel F, Lubich V, Vetter P, Grimm W. Handbook of Plastic Mould Steels. Wetzlar: Edelstahlwerke Buderus AG; 2004.

10 Mold-tech. Texturing in depth: everything you need to know about texturing your mold. [Acessado em 20 nov. 2012.] Disponível em: http://www.moldtech.com/texturing/Texturing-In-Depth.pdf.

11 Mesquita RA, Schneider R. Tool steel quality and surface finishing of plastic molds. Exacta. 2010;8(3):307-318.

12 Sant'anna JP. O segredo é a alma do negócio. Revista Plástico Moderno. 2003;jul.(345). [acessado em 19 nov. 2012]. Disponível em http://www.plasticomoderno.com.br/reportagem. php?rrid=554\&rppagina=1.

13 Catálogo Villares Metals - Aços para Ferramentas. Janeiro, 2012. 